\title{
The Lived Experience of Hospitalized Pregnant Women Having Antiphospholipid Syndrome with a Previous Fetal Loss: A Phenomenological Study
}

\author{
Fatma Zaghloul Mahmoud, Yousria Ahmed Elsayed*, Abeer Saad Eswi \\ Maternal and Newborn Health Nursing, Faculty of Nursing, Cairo University, Cairo, Egypt
}

Email address:

yousria25@gmail.com (Y. A. Elsayed)

${ }^{*}$ Corresponding author

\section{To cite this article:}

Fatma Zaghloul Mahmoud, Yousria Ahmed Elsayed, Abeer Saad Eswi. The Lived Experience of Hospitalized Pregnant Women Having Antiphospholipid Syndrome with a Previous Fetal Loss: A Phenomenological Study. Rehabilitation Science. Vol. 5, No. 1, 2020 , pp. 5-11. doi: $10.11648 /$ j.rs.20200501.12

Received: September 12, 2019; Accepted: October 17, 2019; Published: September 3, 2020

\begin{abstract}
Background: antiphospholipid syndrome is a disorder of the immune system that is characterized by poor obstetric outcome. Women with this disorder may experience devastating problems during pregnancy. Aim: to explore the lived experience of hospitalizedpregnant women having antiphospholipid syndrome with a previous fetal loss. Design: A phenomenological qualitative research design was used with purposive sample of 15 participants. Setting: the high-risk pregnancy department at obstetrics and gynecology hospital which is affiliated to Cairo University Hospitals. Data were collected through semi-structured questionnaire using digital voice recording. Results: uncertainty was the core concept that reflected the experience of the pregnant women under study. This was represented in three major phases: uncertainty before diagnosis with APS, uncertainty after diagnosis, and uncertainty during hospitalization. Seven themes emerged from the data analysis as consequence to uncertainty as follows: living in uncertainty; social burden; psychological suffering; fear of the unknown; stressful hospitalization; threats; and unsettled quality of life. Conclusion: women with antiphospholipid perceived the need to provide them with informational support due to the confused state of mind, threats, lack of knowledge and understanding they expose before and after being diagnosed with APS, and during hospitalization. Recommendation: providing informational support for these women is necessary to meet their needs, improve clinical practice and reduce the negatives consequences of this condition for women during childbearing period.
\end{abstract}

Keywords: Antiphospholipid Syndrome, Fetal Loss, Qualitative Research

\section{Introduction}

Antiphospholipid syndrome (APS) is a systemic autoimmune disease which is characterized by recurrent arterial and venous thrombosis. Pregnancy morbidity associated with APS is manifested by recurrent abortions, fetal losses, early onset of pre-eclampsia, intrauterine growth restriction (IUGR), placental insufficiency and premature delivery [1].

Worldwide statistics have shown that the prevalence of APS in the general population ranges between $1 \%$ and $5 \%$. A population-based study indicated that APS occurred in approximately two persons per 100,000 per year [2]. While in Egypt no accurate incidence represented, but according to what was reported by Rawhya, et al, 2016, the rate of fetal loss in Egypt among pregnant women with APS may exceed $90 \%$ in untreated women [3]. APS is classified into primary APS when it occurs alone and secondary APS when it occurs in association with other conditions such as systemic lupus erythematosus (SLE) [4].

The cause of APS is unknown although there is evidence that genetic and environmental influences have been implicated as potential inducers of APS. Abdel-Wahab, et al (2016) conducted a systematic review of case reports of APS following infection and concluded that development of APS were observed after a variety of infections, most frequently after chronic viral infections with human immunodeficiency and Hepatitis C $[5,6]$. 
APS is recognized as a common disorder and once diagnosed, is treatable. However, for many patients diagnosis is often delayed, sometimes for years, with a consequent disability, limitation in activities of daily living, loss of livelihood, inability to start a family or even death. A pregnant woman diagnosed with APS should have had at least 1 clinical condition and have met 1 laboratory criterion. The clinical criteria include (1) objectively confirmed arterial, venous, or small vessel thrombosis, (2) pregnancy morbidity consisting of either recurrent fetal loss before the 10th week of gestation or 1 or more unexplained fetal deaths at, or beyond, the 10th week of gestation, or (3) premature birth due to placental insufficiency, eclampsia, or preeclampsia. Laboratory criteria include medium- or hightiter immunoglobulins $\operatorname{IgG}$ or $\operatorname{IgM}$ anticardiolipin or the presence of lupus anticoagulant on 2 or more occasions that are at least 6 weeks apart [7].

The literature reports additional symptoms as anxiety, depression, and sorrow as experienced with pregnancy loss in general [8]. The purpose of the current study is to explore the lived experience of hospitalized pregnant women having antiphospholipid syndrome with a previous fetal loss.

\subsection{Significance of the Research}

Pregnant women with APS hospitalized early in pregnancy and stay for a long period of time receiving medical treatment. This is associated with many stressors. Based on the literature, there are scarce researches in Egypt that assess the lived experience of hospitalized pregnant women who have antiphospholipid syndrome and its complication. The findings will add to the body of nursing knowledge in this neglected area. The results of this study may improve the understanding of the condition and provide them with adequate support they need, also may provide greater insight to increase awareness of APS and related complications among practicing nurses and health care provider for the aim of improving pregnancy out come for pregnant women with APS.

\subsection{Aim of the Research}

To explore the lived experience of hospitalized pregnant women having antiphospholipid syndrome with a previous fetal loss.

\subsection{Research Question}

What is the lived experience of hospitalized pregnant women having antiphospholipid syndrome with previous fetal loss.

\section{Subjects and Method}

\subsection{Research Design}

A qualitative research design using the phenomenological approach was used to describe the lived experience of hospitalized pregnant women having antiphospholipid syndrome with previous fetal loss. According to Sloan, \&
Bowe (2014) [9] phenomenology is the study that fits well to detect people's experience on a specific phenomenon, and is focusing on seeking the essence of human experienced phenomena through the analysis of verbal explanations from the viewpoint of the participants.

\subsection{Setting}

The study was conducted at the high-risk pregnancy department at obstetrics and gynecology hospital which is affiliated to Cairo University Hospitals.

\subsection{Sample}

A total of 15 participants met the following eligibility criteria: any pregnant woman who had one or more previous fetal losses associated with antiphospholipid syndrome (APS) either primary or secondary APS; at any reproductive age. The predetermination of the number of participants in qualitative studies is almost impossible as the sample size in qualitative designs is not determined by the number of participants rather by achieving saturation of data; saturation is evidenced when no new information was heard about the study phenomenon.

\subsection{Tools for Data Collection}

An interview questionnaire that included two parts; one for socio-demographic data, past and present obstetric history; and one for the open-ended questions in order to help the pregnant women having antiphospholipid syndrome to express their lived experience.

\subsection{Ethical Considerations}

A primary approval was granted from the Ethical Research Committee at faculty of nursing, Cairo University to carry out the current research in November 2017. All participants were provided with information sheets detailing the aim of the study and the study process; they were also given the opportunity to ask questions about the research; and were fully assured that they could withdraw from the study at any time without any negative consequences. Participant informed consent was obtained prior to commencement of data collection. Anonymity and confidentiality of personal recorded data were assured through coding as well as keeping the recorded tapes in a safe locked place. Participants were also assured that their personal data will not be used for other research purposes without their permission.

\subsection{Procedures}

Once permission was granted to proceed with the proposed study, pregnant woman who met the inclusion criteria of the study were recruited. Direct face to face contact was initiated through individual interviews; every participant was interviewed individually three times once weekly for three weeks. Each interview session ranged from 35-40 minutes and conducted in thenative language of the participants. A 
quiet place, at the high-risk pregnancy department at the conference room was used to conduct the interviews.

The first individual interview session concentrated upon verbal explanation of the nature and purpose of the study as well as signing written informed consent for voluntary participation and using the digital voice recording. Data related to socio-demography, obstetric, medical history, and menstrual history was obtained. The second interview was guided by the first two open-ended questions (1. Describe your feelings, thoughts, and perceptions of your pregnancy loss/losses before and after receiving the diagnosis of APS as accusative factor for such lossess. 2. How has the experience of having APS affected the current pregnancy?).

While in the third interview the other three open-ended questions were (1. Tell me your experience in the current pregnancy during hospitalization as had pregnancy loss associated with antiphospholipid syndrome. 2. Having APS, What are your needs, concerns related to the current pregnancy? 3 How did APS affect your quality of life (physical, social, emotional and economic status?), that was utilized to collect data related to the experience of pregnant women having APS. Field notes also were used for recording any observation that the investigator performed during the interview sessions. Interviews ended when participants exhaust their descriptions of their experience and when no new codes, categories, and themes are emerging as well as there are repetitions of similar data among participants (data saturation). By the end of third interview the research investigator informed each participant that they will be contacted after the completion of data analysis to review the data interpretation (member check).

\section{Data Analysis}

The data analysis for the current study was based on Colaizzi's 1978 phenomenological method. In this study, transcription of the audiotape was done by the research investigator in handwriting word by word after each interview; the researcher went through the transcripts line by line and word by word very closely, extracting significant statements and coding each of them. Then the codes were merged into categories; which were then clustered together into subthemes; then, majorthemes. The integration of the major themes into exhaustive description of the phenomenon, and validating the identified structure and nature of the phenomenon from the participants' description was then done as a final step.

\section{Results}

\section{Profile of the Participants}

Participants' age ranged from 24 to 41 years old. Twelve of them lived in rural areas. Thirteen participants were housewives. Three of them can't read and write; six of them completed their technical/secondary education, and three of them completed their university education. Their distribution according to obstetrics code is shown in (table 1).

\subsection{Theme 1: Living in Uncertainty}

\subsubsection{Confusion with Delayed Diagnosis}

The pregnant women described the experience of pregnancy loss before being diagnosed with APS, as having to exist in a somewhat confused state of mind, they found themselves in an unexpected situation which was absolutely different from their expectations, many women had to consult a number of physicians from various medical specialties to receive a conclusive diagnosis, and this leads to delay in diagnosis. Most women attributed the delay in the diagnosis of APS and the repeated pregnancy losses to medical ignorance.

Participant 1:

"I visited so many doctors and went to many clinics. I didn't know what to do, and I was confused. I did not know what my condition was, and I was very sad because I couldn't find any solution for my condition. After my six miscarriage, I went to see a doctor in El-mohands in area; he told me that I had a blood clotting problem. Later on, I went to Qasr al-Aini hospital and after a year and 3 months of treatment and follow up, I got pregnant".

Participant 8:

"We took a long period of time to know the cause of my fatigue after the death of the second fetus; the doctor told me that I had SLE and APS".

Table 1. Distribution of the participants according to their personal data $(n=15)$.

\begin{tabular}{|c|c|c|c|c|c|c|c|}
\hline Participants code & Age & Education & occupation & $\begin{array}{l}\text { No. of } \\
\text { pregnancies }\end{array}$ & $\begin{array}{l}\text { No. of } \\
\text { abortions }\end{array}$ & $\begin{array}{l}\text { No. of preterm } \\
\text { babies }\end{array}$ & $\begin{array}{l}\text { No. of } \\
\text { living child }\end{array}$ \\
\hline Participant (1) & 24 & Can't read \& write & housewife & 7 & 6 & 0 & 0 \\
\hline Participant (2) & 27 & primary & housewife & 7 & 4 & 2 & 0 \\
\hline Participant (3) & 41 & Can read \& write & housewife & 5 & 3 & 1 & 0 \\
\hline Participant (4) & 32 & Secondary/tech. school & housewife & 4 & 3 & 0 & 0 \\
\hline Participant (5) & 35 & University degree & housewife & 7 & 2 & 0 & 2 \\
\hline Participant (6) & 34 & Secondary/tech. school & housewife & 4 & 0 & 2 & 1 \\
\hline Participant (8) & 30 & Secondary/tech. school & housewife & 4 & 0 & 2 & 1 \\
\hline Participant (9) & 24 & Can't read \& write & housewife & 4 & 3 & 0 & 0 \\
\hline Participant (10) & 30 & university degree & Worker & 4 & 2 & 0 & 1 \\
\hline Participant (11) & 34 & university degree & housewife & 5 & 1 & 1 & 1 \\
\hline Participant (12) & 28 & preparatory school & housewife & 8 & 6 & 1 & 0 \\
\hline Participant (13) & 28 & Secondary/tech. & Worker & 6 & 4 & 0 & 1 \\
\hline Participant (14) & 31 & Can't read \& write & housewife & 14 & 12 & 0 & 1 \\
\hline
\end{tabular}


Table 2. The themes and subthemes related to the lived experience for pregnant women having APS.

\begin{tabular}{ll}
\hline Themes & Subthemes \\
\hline living in uncertainty & (a) feeling confusion with delayed diagnosis \\
social burden & (b) frequent unexplained baby loss \\
psychological suffering & (a) marital divorce \\
& (b) family pressure, negative attitude from husband and mother in law \\
Fear of the unknown & (a) feeling sad and frustrated \\
& (b) delayed pregnancy up to 3 years \\
stressful hospitalization & (a) experienced confusion \&fears of infertility \\
& (b) lack of knowledge about treatment \\
threats & (a) Boring hospital stay \\
(b) separation from family \\
unsatisfied with quality of life & (c) lack of information \\
\hline
\end{tabular}

\subsubsection{Frequent Unexplained Baby Loss}

Participant 12:

"I miscarried seven times; the first baby was delivered naturally at the seven month, the second was delivered by CS at the fifth month, the third was delivered normally at the fifth month and the others at forty days".

\subsection{Theme 2: Social Burden}

\subsubsection{Marital Divorce}

Seven participants described how the entire experience of loss of pregnancy has social impact in their life, two cases were divorced and all participants had problems with husbands and mother in law.

Participant 2:

"I lived a tragedy with my first husband. I didn't use any contraceptive method all the previous days, because my husband was so determined to have children. The first time I delivered a baby girl by CS, but she died three days later. Then I had four miscarriages. The doctor shouted at my face and advised me to rest and take contraceptive method. This is the only time my husband agreed to let me use contraceptive method. But one month after that I got pregnant with the last baby that I delivered by CS and died and this was the end of my relationship with my husband".

\subsubsection{Family Pressure, Negative Attitude from Husband and Mother in Lawparticipant 1}

"I was always in trouble with my husband's family, and my mother in law wanted him to find another wife, and she always reproached and reviled me".

Participant 12:

"Everyone around me was frustrated, including my husband, because he knew that the doctors told me that the baby may die because I had varicose veins in the esophagus, and they were on the verge of exploding, and the doctors were forced to stop giving me Clexane for ten days until they did the endoscope and inject them, my husband didn't even ask about me".

\subsection{Theme 3: Psychological Suffering}

\subsubsection{Feeling Sad and Frustrated}

Feelings of frustration and sadness were expressed a number of ways by all participants in this study. Some demonstrated these feelings after divorce but for others, these feelings occurred when they aborted more than one time; Ignorance of the cause of abortion and death of the baby inside the uterus, the confusion state that they lived, and loss of motherhood and pressure from the family all added to their frustration and sadness.

Participant 13:

"When I aborted several times I was very sad and did not know the reason so I went to many doctors and no one could diagnose my case".

Participant 13:

"I stayed divorced for 11 years, but I had no wish to remarry again".

\subsubsection{Delayed Pregnancy up to 3 Years}

From the factors that caused psychological burden was delayed pregnancy. Five participants experienced delayed pregnancy.

Participant 3:

"I got married at the age of 20 years, and I stayed 3 years without getting pregnant.

Participant 5:

"After my first abortion, I stayed without pregnancy for four years, so I went to a doctor and became pregnant using ovulation stimulation drug. I don't know why I took this ovulation stimulation drug, while I got pregnant naturally the first time".

\subsection{Theme 4: Fear of the Unknown}

\subsubsection{Experienced Confusion \& Fears of Infertility}

The women described the experience ofperinatal losses after diagnosis of APS, as still having confusion because they didn't have any information about the disease and the causes for acquiring such a disease, mixed with a perplexity of 
psychological emotions such as fear, sadness, confusion, frustration, fears from infertility.

Participant 3:

"The doctors told me that I have APS. I didn't know how it happens, why it happens or what it causes it. I was confused and asked the doctors how these things happened. They told me that sadness is the reason, but everybody gets happy and sad from time to time".

Participant 3:

"I was afraid that this disease can affect my chances to have children in the future".

\subsubsection{Lack of Knowledge About Treatment}

Participant 4:

"The doctors didn't explain to me the nature of my disease. Will I ever recover from it? Can I have children in the future?

\subsection{Theme 5: Stressful Hospitalization}

The pregnant women having APS described their experience during.

hospitalization as living with many stressors like worries and concerns about the fetus; separation from family; lack of information about their medical condition; unfamiliar environment; unusual smell around them; unfavorable food; worries about other family members at home; boredom of hospital stay; loneliness; feeling of imprisonment; sense of timelessness; lack of control; uncertainty; frequent procedures; inability to understand medical words; and anticipating bad health problems or death of the baby; and fear of putting the baby in the neonatal intensive care units.

Participant 2:

"I feel trapped. For three months, I sleep and awake up on the same bed. I feel like I am in a prison".

Participant 4:

"This feeling is unbearable. I feel trapped, not living my normal life, and not living freely. I am so depressed. I see my family only at visiting hours. I am bored with everything, from the people around me, from staying here. Without my family, I don't know how to practice my life and I hope this time will pass on a good way".

Participant 4:

"No one is talking to me or gives me any advice, neither nurses nor doctors".

Participant 5:

"The doctors don't care to give us advice. I want to ask them about many things, but they don't give us a chance to ask".

Participant 8:

"There is nothing good in the hospital. Neither the nurses nor the doctors treat us well. Even nursing staff always shout at us and give us orders, as if we aren't patients. Actually, not all of them treat us badly. Some people are good and some are not, even the doctors".

\subsection{Theme 6: Threats}

Fear of losing the baby \& getting abundant by my husband.
Participant 2:

"I am scared to lose my baby, and this would be the last shock because I won't be able to repeat it again because I will be tired".

"I'm afraid of losing my pregnancy like I did three times before. I'm like any woman who wants to be a mother. I hope to carry my baby in my arms (she cried) I hope to complete my pregnancy safely and see my son".

Participant 2:

"I am afraid of my husband getting married again, because he wants to have a baby, and I'm afraid to get divorced again. I hope everything would be ok".

\subsection{Theme 7 Unsettled Quality of Life}

The pregnant women described how the entire experience of having APS affected their personal well-being, with great physical suffering, social conflicts, psychological complaints, and economic burden.

Participant 2:

"My life is not the same as before. I mean I used to work actively, and stay for twelve hours on my feet. After what happened to me, if I go to cook some food, I do it with great effort, and if I go somewhere, I return home tired, and my body would hurt me for two days. I feel that my health is no longer the same".

Participant 2:

"My relationship with others was not affected, but I was divorced from my first husband".

Participant 4:

"The stroke affected me badly, and it made unable to visit others. The stroke also affected my intimate relationship with my husband".

Participant 1:

"I was psychologically affected, and I felt fear, anxiety and terror".

Participant 9:

"I'm psychologically tired. All the time Ifear a lot for the fetus and I fear that a stroke will happen to me. I'm always afraid, and I'm not living the life I should; to have peace of mind and hope that the pregnancy will be completed safely. I live most of the time worrying that something will happen to me".

Participant 2:

"I could not buy Clexane, so I had to be booked in the hospital".

Participant 5:

"Concerning the injections, the financial conditions were hard, so I couldn't buy them on my expenses. I was very upset and kept thinking about how to get the money. I was forced to ask my friends for money, and it hurt my feelings".

\section{Discussion}

Findings of the current study indicated that the participants experienced uncertainty before and after diagnosis. Uncertainty before diagnosis was displayed in 3 main themes: a) living in uncertainty, b) social burden, and c) 
psychological suffering.

These findings were consistent with Mathew, Cesario, \& Symes (2008) [10], who conducted a phenomenological analysis for experiences of women with antiphospholipid syndrome and found two themes that caused bewilderment in the patients. One was their perception of little knowledge of APS among physicians which lead to delayed diagnosis and put the women in puzzlement by not having an answer to the repeated losses and to having a disease that is not very well known at the time even in the medical community.; the second, a lack of information for women that had sustained a fetal loss.

These findings also were similar to the findings of Georgopoulou et al, (2015) [11] who describe the healthrelated quality of life (HRQoL) for people with APS and stated important issues reported by patients such as; lack of information and presence of subjective symptoms with the absence of objective signs were associated with difficulty/delay in getting a diagnosis, doubts about the existence and severity of the illness, lack of understanding and contribute to disbelief. In contrary, Georgopoulou et al, (2015) at the same study reported findings that were not inconsistent with the study findings such as, medication unpredictability and fear of side effects as it attributed to the increased risk of hemorrhage associated with anticoagulants. Uncertainty about medication side effects and symptoms can have a negative impact on stress and severity of the illness.

Radford and Hughes (2015) [12] conducted a structured literature review of qualitative literature on women's experience of early miscarriage, he mentioned that, women who experience losses associated with causes other than APS may grieve the lost pregnancies and infants and suffer the psychosocial consequence of losses. Women with APSrelated losses grieve not only the loss of pregnancies but also the loss of personal health and constantly worry about the fatal complications of APS for themselves and the offspring. Unlike women in general perinatal loss population, women who are diagnosed with APS always live in a confused state of mind because this medical condition is not well understood in medicine and other healthcare disciplines. As a result, they perceived the need to consistently update themselves with information and new knowledge about APS to experience a positive perinatal outcome and sustain lives.

Findings from the study indicated that the participants hospital stay added to their uncertainty during hospitalization, they were exposed to certain stressors and threats. These findings matched those of Abdel Nabi, (2017) [13] who conducted a study to assess the effect of emotional support on perceived stress among hospitalized high-risk pregnant women, and found that stressors reported by mothers; three quadrant of the women had changes in sleeping pattern due to hospitalization as insomnia and interrupted sleeping, more than half expressed worries about the fetus and unsuitable environment as unsuitable food, beds and bathroom, less than half separation from family, feeling burden on the family due to hospital visiting, and fears from unknown, lower scores of stress were given to hospital routines, feeling bored of long hospital stay and lack of information about the fetus condition, the report of ultrasound, the diagnosis and procedures related to their condition.

While Meaney, Corcoran, \& Spillane, (2017) [8] who conducted interpretative phenomenological study about experience of miscarriage revealed that, the participants stated that any negative experiences in the hospital were related to the administration and the physical design of the hospital as it lacked privacy which prevented them to more openly express their worry, anxiety or upset. They described that the physical space heightened their distress as it contained numerous women with varying symptoms with only a curtain between them.

The findings of the present study revealed that, the participants experienced unsettled quality of life in the form of physical suffering due to high level of fatigue and tired especially women who had stroke, social conflicts; women who had stroke mentioned their relations with others were affected, while others mentioned that there were conflicts between them and the mother in law, and others were divorced, psychological complaints; due to the disease complication especially which related to pregnancy and finally economical burden; the expensive price for clexane injection and the low socioeconomic status for the participants lead to economic burden between them.

These findings in agreement with Mathew et al, (2008) [10], who described how the entire experience of perinatal losses and the diagnosis of APS affected personal well-being, with great physical, emotional, social, spiritual, and economic impact. The effects of APS on different body systems, along with the pain of undergoing painful procedures to evacuate the dead fetus, induction of labor, and or emergency cesarean sections following each loss impaired the women's physical health. The women suffered a loss of self-esteem and self-image, as well as their concept of being a woman when they perceived the inability to become mothers, which negatively influenced emotional health.

This feeling increased when their usual friends and relatives, avoided them resulting in disruption of a social network.

Concerning the needs for pregnant women having APS in the current pregnancy, it included dreams for having a child and need information about the disease, and regarding the pregnant women having APS concerns in the current pregnancy it included fearing from losing her baby, fearing from delivering unhealthy baby, and occurring of bleeding at delivery, and fearing from abandonment of the husband.

These finding matched with de Jesus et al 2014 [14], who clarified some of the APL-related concerns in APL-positive pregnant patients included: miscarriage, preterm delivery, intrauterine growth restriction, and blood clots during pregnancy and up to six weeks following the birth of the baby, while Andreoli et al, 2017 [15] clarified that the concerns and needs of women with APS included; the effect of pregnancy on maternal disease, the impact of disease activity on fetal health and the safety of medications during 
pregnancy, breastfeeding, and use of contraception

\section{Conclusions}

Women with antiphospholipid perceived the need to provide them with informational support due to the confused state of mind, lack of knowledge and understanding they expose before and after being diagnosed with APS, and during hospitalization. They exposed in their life to social burden, psychological suffering, fear of the unknown, many types of threats, many hospitalization stressors they exposed to it during their hospital stay, and unsettled quality of life from all aspects; physical, social, psychological, and economic aspects. The findings from this study may enrich the existing scientific body of knowledge in nursing, and help the women to improve their quality of life.

\section{Recommendations}

Providing informational support for these women is necessary to meet their needs, improve clinical practice and reduce the negatives consequences of this condition for women during childbearing period

\section{Acknowledgements}

The authors announced their gratitude and appreciation to all pregnant women for their participation and cooperation in the research study, as well as the health care workers in the high-risk pregnancy department at obstetrics and gynecology Cairo University Hospital.

\section{References}

[1] Rezk M, Dawood R, Badr H. (2016): Maternal and fetal outcome in women with antiphospholipid syndrome: a three year observational study; The Journal of Maternal-Fetal \& Neonatal Medicine. 29 (24).

[2] Duarte-Garcia A, Pham M, Crowson CS, Moder K, Pruthi R, Matteson EL. (2017): Epidemiology of Antiphospholipid Syndrome: A Population-Based Study [abstract]. Arthritis Rheumatol. $\quad 69 \quad$ (suppl https://acrabstracts.org/abstract/epidemiology-ofantiphospholipid-syndrome-a-population-basedstudy/Accessed September 8, 2018.

[3] Rawhya R, Zein E, Rashad A, Ibrahim T, et. al. (2016): Catastrophic Antiphospholipid Syndrome in Egypt: Hindawi Publishing Corporation Case Reports in Rheumatology. Volume 20, Article ID 4161439, 4 pages http://dx.doi.org/10.1155/2016.
[4] Cervera R. Antiphospholipid syndrome. (2017): Thromb Res. Mar. 151 (1): S43-S47. [Medline].

[5] Sebastiani GD, Iuliano A, Cantarini L, Galeazzi M. (2016): Genetic aspects of the antiphospholipid syndrome: An update. Autoimmune. Rev 15 (5): 433-9. Doi 10.1016/j.autrev.2016.01.005. Epub 2016 Jan 21.

[6] Abdel-Wahab N, Lopez-Olivo M, Pinto-Patarroyo GP, SuarezAlmazor ME. (2016): Systematic review of case reports of antiphospholipid syndrome following infection. Lupus. (25), $1520-1531$

[7] Miyakis S, Lockshin MD, Atsumi T, et. al. (2006): International consensus statement on an update of the classification criteria for definite antiphospholipid syndrome. J Thromb Haemost. 4: 295-306.

[8] Meaney S, Corcoran P, Spillane N, et. al. (2017): Experience of miscarriage: an interpretative phenomenological analysis. BMJ Open. 7: e011382. doi: 10.1136/bmjopen-2016- 011382.

[9] Sloan A. \& Bowe B. (2014). Phenomenology and Hermeneutic Phenomenology: the Philosophy, the Methodologies and Using Hermeneutic phenomenology to investigate Lecturers Experiences of Curriculum Design. Quality \& Quantity, 48 (3), 1291-1303.

[10] Mathew S, Cesario S, Symes L. (2008): Explaining unexplainded perinatal loss. Experiences of women with antiphospholipid syndrome. J Perinat Neonat Nurs. 22: 293301.

[11] Georgopoulou s, Efraimidou s, Jane MacLennan s, Ibrahim f, \& Cox t. (2015): Antiphospholipid (Hughes) syndrome: Description of population and health related quality of life using the SF-36. lupus; 24, 174-179 http://lup.sagepub.com.

[12] Radford and Hughes (2015), women's experiences of early miscarriages: implication of nursing care, Journal ofclinical nursing. 24, 1457-1465 doi: 10.1111/jocn.12781, John Wiley $\&$ sons Ltd.

[13] Abdel Nabi E. (2017). Effect Of Emotional Support On Perceived Stress Among Hospitalized High Risk Pregnant Women. (Unpublished master thesis). Faculty of Nursing, Cairo university.

[14] De Jesús GR, Rodrigues G, De Jesús NR, \& Levy RA. (2014). Pregnancy morbidity in Morbidity in Antiphospholipid Syndrome: What Is the Impact of Treatment? Current Rheumatology Reports, 16 (2), 403.

[15] Andreoli L, Bertsias GK, Agmon-Levin, Brown s, Cervera R, Costedoat-Chalumeau N Doria A, Fischer-Betz, Forger R et. al. (2017). EULAR recommendations for women's health and the management of family planning, assisted reproduction, pregnancy and menopause in patients with systemic lupus erythematosus and/or antiphospholipid syndrome. Ann Rheum Dis; 76: 4 doi: 10.1136/annrheumdis-2016-209770. 